\title{
Facial Expression Wrinkles and Their Relaxation by a Synthetic Peptide
}

\author{
Remo Campiche ${ }^{1} \mathbb{D}$. Francesca Pascucci ${ }^{1} \cdot$ Lily Jiang $^{2} \cdot$ Thibault Vergne $^{3} \cdot$ Marie Cherel $^{3} \cdot$ Sarah Gougeon $^{3}$. \\ Elodie Préstat-Marquis ${ }^{3}$. Ghislain François ${ }^{3}$. Guillaume Laurent ${ }^{1} \cdot$ Mathias Gempeler $^{1}$
}

Accepted: 19 November 2020 / Published online: 29 November 2020

(c) The Author(s) 2020

\begin{abstract}
Expression wrinkles form over time due to repeated facial movements such as smiling and frowning. They have an imprint on facial skin in areas such as the corner of the eyes, where they take the form of crow's feet, the forehead and the glabella, where they appear as frown lines, and around the mouth, as marionette lines. In the study presented here, we recruited two sets of volunteers. An older group of 57 volunteers aged 50 to 65 years, and a group of eight younger volunteers aged 21-35 who were the biological daughters of eight of the older volunteers. Using VISIA CR, we took images of the volunteers in relaxed, angry and smiling mode to assess similarities in expression wrinkle patterns. In addition, the older volunteers were split into a placebo group and an active group who applied a formulation of $4 \%$ of a cosmetic product containing the peptide diaminobutyroyl benzylamide diacetate (DABBA) for four weeks. Wrinkles were assessed by image analysis, expert grading and Primos ${ }^{\text {lite }}$ measurements. Our study found striking similarities in the facial wrinkle patterns of mothers with relaxed faces and daughters with angry or smiling faces. We found a decrease in visible wrinkles in the group of older volunteers applying DABBA. We created a facial map for graded wrinkles showing these changes. Volunteers using the active formulation showed significantly less wrinkle area and length on the forehead when frowning compared to the placebo group $(\mathrm{p}<0.05)$.
\end{abstract}

Keywords Skin $\cdot$ Expression wrinkles $\cdot$ Relaxation $\cdot$ Facial color map $\cdot$ Peptide

\section{Introduction}

A hallmark of aging skin is the formation of wrinkles. Facial wrinkles appear as fine lines, creases or deep wrinkles (Bazin and Leveque 2011; Zouboulis et al. 2019). They show as frown lines on the forehead and the glabella, crow's feet on the eye's lateral edge and as nasolabial folds, upper lip lines or marionette lines around the mouth (Bazin and Doublet 2007). Wrinkles occur either through chronological aging, or photoaging and are particularly pronounced in photo-exposed areas of the body such as the face (Nkengne and Bertin 2013), neck (Hatzis 2004) and hands (Jakubietz et al. 2008). Moreover, various additional factors to which skin is exposed contribute to aging and wrinkling. These factors are collectively termed the skin aging exposome (Krutmann et al. 2017). With respect

\section{Remo Campiche}

remo.campiche@dsm.com

1 DSM Nutritional Products, Personal Care \& Aroma, Kaiseraugst, Switzerland

2 SGS Stephens Inc., Richardson, TX, USA

3 Newtone Technologies, Lyon, France to wrinkles, the skin aging exposome mainly works on the degradation of skin tissue structures such as the extracellular matrix comprising elastic fibres, collagen and hyaluronic acid (structural changes) (Langton et al. 2010; Shin et al. 2019; Watson and Griffiths 2005). However, particular wrinkle patterns, such as crow's feet, smile lines, or frown lines imprint in the skin due to repeated facial movements and expressions (mechanical changes) (Miyamoto and Hillebrand 2007; Hillebrand et al. 2010). Facial movements occur via contraction of facial muscles. Here, nerve endings release neurotransmitters like acetylcholine which binds to the nicotinic acetylcholine receptor on the muscle surface. This leads to depolarization and the opening of sodium ion channels. Consequently, an action potential propagates along the cell causing calcium channels to open which stimulates contraction via additional calcium release from the sarcoplasmatic reticulum (Kuo and Ehrlich 2015). Expression or mimic wrinkles were termed type 3 wrinkles by Piérard et al. (2003). Hillebrand et al. showed how expression lines turn into persistent wrinkles on the crow's feet area in an 8-year longitudinal study (Hillebrand et al. 2010). Various studies have also dealt with the in silico simulation of expressive wrinkle formation (Kuwazuru et al. 
2008; Zhao et al. 2020; Chavoshnejad et al. 2020), but the topic remains poorly investigated despite the consensus that facial mimic wrinkles eventually turn into persistent wrinkles, a concept already proposed back in the 1980s for the formation of frown lines (Pierard and Lapiere 1989). In addition, preliminary evidence suggests that facial mimic wrinkles form similarly in genetically related individuals such as mothers and daughters (Hillebrand et al. 2010). Facial wrinkles, and expression or mimic wrinkles in particular, can be of cosmetic concern when they become persistent (Nkengne et al. 2008; Blume-Peytavi et al. 2016). There are aesthetic concerns, which can cause psychological distress in many individuals because they show their age, or look older than they are, which is generally considered less attractive (Samson et al. 2010), but there is also the fear of misconception by others, i.e. giving an impression of being constantly angry or annoyed (Willis and Todorov 2006; Tian and Xiao 2016; Song 1998). Along these lines, there is evidence that facial expressions not only convey emotions to the outside world, but also modulate human emotions (Alam et al. 2008; Ekman et al. 1983; Izard 1990). Due to these many reasons, the cosmetic relaxation of facial mimic wrinkles has become a sought-after treatment in aesthetic dermatology (Becker-Wegerich et al. 2001). Botulinum toxin A has established itself as the number one treatment in this area (Franca et al. 2017). It reversibly paralyzes facial expression muscles by inhibiting the release of acetylcholine on nerve endings, thus preventing muscle depolarization. The aesthetic physician injects the toxin subcutaneously to induce muscle relaxation at distinct facial areas (Small 2014). In addition, non-invasive treatments using cosmetic peptides such as diaminobutyroyl benzylamide diacetate (DABBA) have been developed and have shown skin smoothing activity in vivo (Campiche et al. 2017) by mimicking botox-like activity. Since movement of facial muscles furthers the imprint of expression wrinkles, it is likely that suppression of facial muscle movement may delay the imprint of expression wrinkles over time. Therefore, patients have started using botulinum toxin $\mathrm{A}$ at an earlier age, usually at lower dosages (Kinonen 2017).

In the study presented here, we investigated facial mimic wrinkle formation in biological mothers and daughters. We provide new evidence for the peptide DABBA and its ability to relax facial expression wrinkles and also introduce a novel facial color map for wrinkle grading to investigate and display the efficacy of anti-aging treatments.

\section{Materials and Methods}

\section{Test Formulations}

The test formulations consisted of a placebo formulation and an active formulation of $4 \%$ of a commercial product containing 2500 ppm of DABBA (Trade name SYN®-AKE,
DSM Nutritional Products, Switzerland). The composition of both placebo and active formulation is outlined in Table 1 .

\section{Study Outline and Volunteers}

This human study was conducted at SGS Stephens Inc. (formerly Thomas J. Stephens \& Associates Inc.), Richardson, TX, United States. The study took place between 8th July and 22nd September 2019. This was a single centre, placebo-controlled, randomized, and double-blind study. This study adhered to the guidelines of the declaration of Helsinki. Volunteers gave their informed consent to participate in the study. The study was approved by the local ethics committee, IntegReview Institutional Review Board (IRB) on 25th June 2019. IntegReview IRB, located in Austin, Texas, is a duly constituted IRB under Title 21 CFR Parts 50 and 56. Volunteers were female: 54 Caucasian, 2 Asian, and 1 mixed race, ages 50 to 65 years. For the wrinkle pattern analysis, we recruited eight additional volunteers (7 Caucasian, 1 Asian) who were biologically related daughters to eight of the volunteers. Subjects were in good general health (physical, mental, and social well-being, not merely the absence of disease/infirmity), according to a self-report, and had Fitzpatrick skin type I-IV. The 8 daughters were 21-35 years old and had no to a mild score for wrinkles on the overall face (score of $0-3$ according to a modified Griffiths scale, where $0=$ none and $9=$ severe). Volunteers in the 50-65 age group had mild to moderate scores (score of 3-6 according to a modified Griffiths scale, where $0=$ none

Table 1 Composition of formulations used in this study

\begin{tabular}{lll}
\hline INCI & $\begin{array}{l}\text { Product A } \\
\text { (placebo) }\end{array}$ & $\begin{array}{l}\text { Product B } \\
\text { (containing } \\
\text { DABBA) }\end{array}$ \\
\hline Aqua & 66.72 & 66.72 \\
Disodium EDTA, Aqua & 0.05 & 0.05 \\
Xanthan gum & 0.20 & 0.20 \\
Propanediol & 10.00 & 10.00 \\
Cetearyl olivate, sorbitan olivate & 3.00 & 3.00 \\
Polysorbate 20 & 0.50 & 0.50 \\
Stearic acid, palmitic acid & 1.00 & 1.00 \\
Isopropyl myristate & 4.00 & 4.00 \\
Isostearyl isostearate & 4.00 & 4.00 \\
Dicaprylyl ether & 4.00 & 4.00 \\
Phenoxyethanol, ethylhexylglycerin & 1.00 & 1.00 \\
Dimethicone & 1.00 & 1.00 \\
Hydroxyethyl acrylate/sodium acry- & 0.50 & 0.50 \\
$\quad$ loyldimethyl taurate copolymer & & \\
Glycerin, aqua, dipeptide diaminobu- & - & $\mathbf{4 . 0 0}$ \\
$\quad$ tyroyl benzylamide diacetate & & \\
Aqua & $\mathbf{4 . 0 0}$ & - \\
Sodium hydroxide, Aqua & 0.03 & 0.03 \\
\hline
\end{tabular}


and $9=$ severe) for wrinkles in at least 3 of the following locations: Forehead, Crow's feet, Nasolabial (nose to corners of mouth), Marionette (corners of mouth down to chin). Subjects were willing not to use any foundation during the course of the 4-week study (lip and eye color cosmetics were allowed), not had any facial treatments in the past 6 months, and were willing to withhold all facial treatments during the course of the study.

Exclusion criteria: Standard exclusion criteria were applied. In brief: having known allergies to facial skin care products; to be nursing, pregnant, or planning to become pregnant according to self-report; a history of skin cancer within the past 5 years; to be taking or have taken anti-aging or skin lightening products, or other products or topical or systemic medication known to affect skin aging or dyschromia, during the two weeks before the study.

\section{Assignment and Application of Test Formulations}

Randomization: Validated software (RITA, Randomization in Treatment Arms) was used to assign the test products to the subgroups in a way that minimized potential imbalance regarding age, phototype and ethnicity. Product A received 28 subjects. Product B received 29 subjects. Application: Twice per day (morning and evening), after facial cleansing, a nickel-sized amount $\left(2 \mathrm{mg} \mathrm{cm}^{-2}\right)$ of test material was applied over the entire face and allowed to absorb.

\section{Image Acquisition}

Subjects had images taken at the baseline and week 4. Subjects acclimatized to ambient conditions within the clinic for at least $15 \mathrm{~min}$ before any photographs were taken. Digital images of each subject's face were taken using VISIA CR photo station (Canfield Imaging Systems, Fairfield, NJ, USA) with a Canon Mark II digital SLR camera (Canon Incorporated, Tokyo, Japan). Subjects adopted a neutral, unsmiling expression for images taken from left, center, and right views. At the baseline and week 4, an additional center view image was taken with an "angry" frowning expression, and an additional left view image was taken with a wide smiling expression. In order to standardize this procedure as much as possible, subjects were asked to assume as angry an expression as possible and to assume as wide a smile as possible at both timepoints. A 48 patches color chart (Newtone Technologies, Princeton, NJ, USA) was added to the system and present on each image.

\section{Primos $^{\text {lite Imaging Procedures }}$}

Primos ${ }^{\text {lite }}$ imaging was performed on crow's feet area. The Primos ${ }^{\text {lite }} 45 \times 30 \mathrm{~mm}$ system (GFMesstechnik GmbH, Teltow, Germany) is a hand-held 3D imaging device for assessing the microtopography of skin. The field of view is $45 \times 30 \times 20 \mathrm{~mm}$ with resolution of $61 \times 61 \times 6 \mu \mathrm{m}$. Primos ${ }^{\text {lite }}$ images were analyzed using the Primos ${ }^{\text {lite }}$ wrinkle analysis software built-in function (Widgerow, Jiang, and Calame 2018).

\section{Clinical Grading of Efficacy Parameters}

At the baseline and week 4, subjects were evaluated for wrinkles on the forehead, crow's feet, nasolabial folds, marionette area, and upper lip according to a modified Griffiths scale (Griffiths et al. 1992).

\section{Wrinkle Analysis of Angry and Smiling Faces and Visual Enhancement}

In order to study the evolution of wrinkles over time, the wrinkles were segmented using specific image processing algorithms. Then the wrinkles were characterized by computing their conspicuous surface area, length, and volume (Campiche et al. 2019). In addition to the analysis, two types of illustration were created to visualize the product effect. First, a visual enhancement was performed to highlight wrinkles using an image processing pretreatment. Then, delta values of expert grading scores between the baseline and week 4 were mapped on a 3D face using a pink facial colour map (Newtone Technologies, Lyon, France) (Voegeli et al. 2015, 2019).

\section{Results}

\section{Mimic Wrinkle Patterns in Daughters' Expressive Faces Resemble Patterns in Mothers' Relaxed Faces}

We had eight biological mother-daughter pairs who resembled each other visually as exemplified by the three pairs shown here (Fig. 1a). We compared daughters' expressive faces with their respective mothers in relaxed facial mode and found a similar wrinkle pattern on the glabella when the daughters were frowning (Fig. 1b). In addition, when daughters were smiling, a similar pattern could be seen on their crow's feet compared to their mothers in relaxed mode (Fig. 1c).

\section{DABBA can Smoothen Persistent Facial Mimic Wrinkles}

We have shown previously that DABBA can smoothen facial wrinkles on both forehead and crow's feet (Campiche et al. 2017). We confirm these data here using a slightly different measuring device (Primos ${ }^{\text {lite }}$ ) which delivers metric values. Looking at the crow's feet of subjects in the 50 to 
(a)

\section{Mother-Daughter pair A}

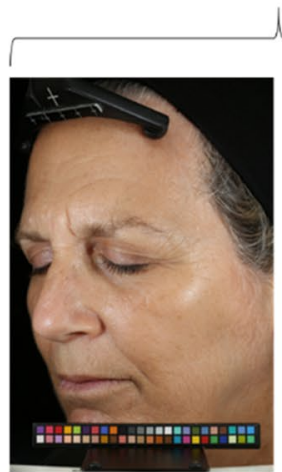

(b)
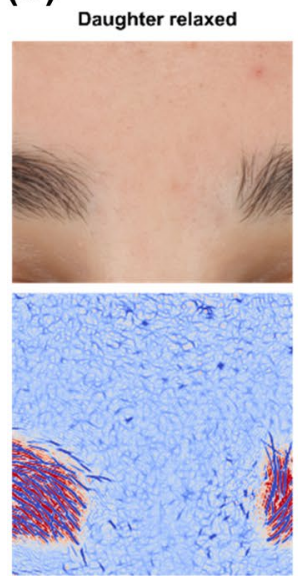

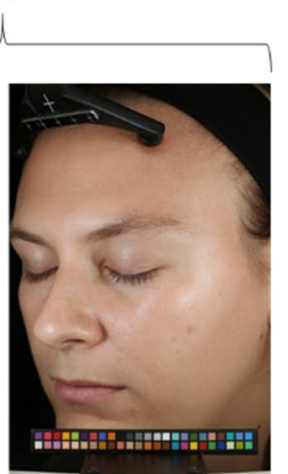

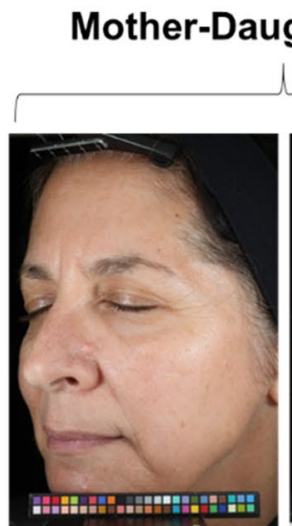

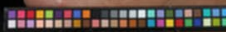
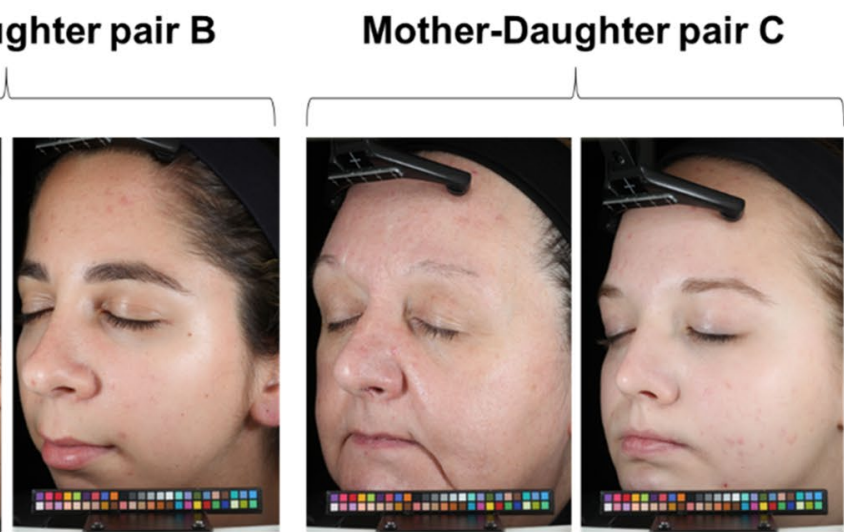

(c)

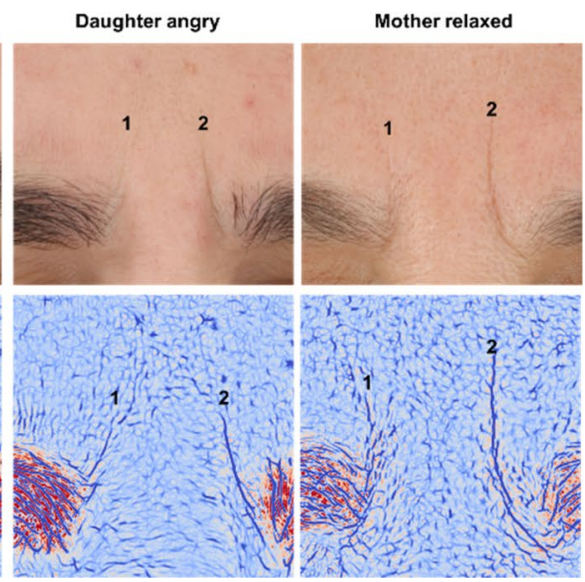

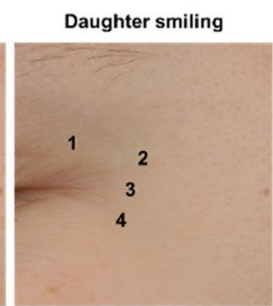
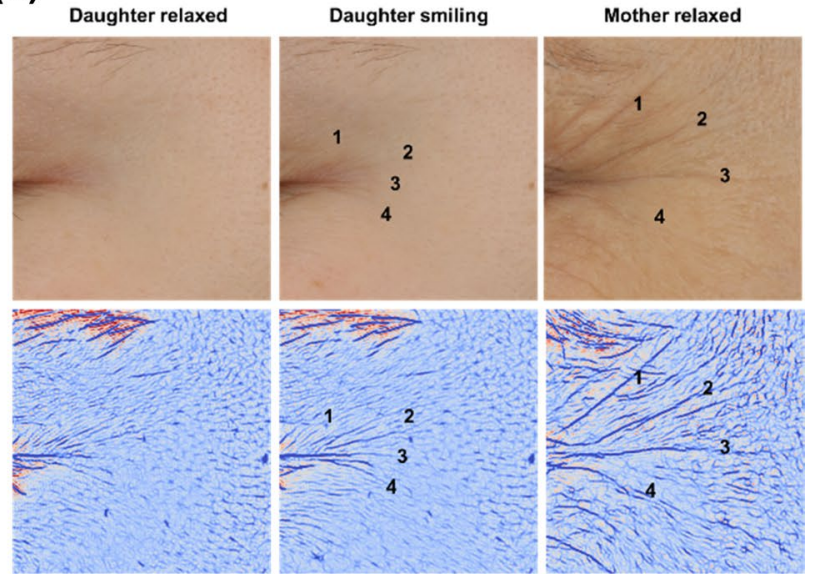

Fig. 1 Resemblance of daughters and mothers. a Side view of biological mother-daughter pairs participating in the study. They clearly look alike. b) Frown lines on the glabella of the daughters' angry face look similar to the ones on the mother's relaxed face. Frown lines 1 and 2 form in the daughter when she pulls an angry face and are extended at the same place on the mothers' relaxed face. The lower panel shows a wrinkle enhancement highlighting the wrinkles pre-

65 age group, we measured a reduction in wrinkle length of $-3.48 \mathrm{~mm}$ after 2 weeks ( $<0.05$ vs baseline), and of $-3.38 \mathrm{~mm}$ after 4 weeks ( $\mathrm{p}=0.094$ vs baseline) (Fig. 2a). In addition, we measured a decrease in wrinkle area of $-0.66 \mathrm{~mm}^{2}$ after 2 weeks and of $-2.1 \mathrm{~mm}^{2}$ after 4 weeks ( $p=0.086$ vs baseline) (Fig. $2 b)$. The visible effects can be seen in the examples in Fig. 2c (volunteer \#8) and Fig. 2d (volunteer \#52) which both show the crow's feet area at the baseline and week 4 with decreased wrinkles at week 4 .

\section{Expert Grading of Facial Wrinkles in 'Mothers' Shows a Wrinkle Decrease After 4 weeks of DABBA Use}

In addition to Primos ${ }^{\text {lite }}$ measurements, we employed expert grading to assess the visual improvement of facial wrinkles when using a formulation containing DABBA. sent in the standard images of the upper panel. c Crows' feet on the edge of the eye of the daughters' smiling face look similar to the ones on the mother's relaxed face. Crows' feet 1, 2, 3, and 4 form in the daughter when she smiles and are extended at the same place on the mothers' relaxed face. The lower panel shows a wrinkle enhancement highlighting the wrinkles present in the standard images of the upper panel

The results of the expert grading are listed in Table 2. We found a change vs the baseline for the group using DABBA of -0.26 units $(p<0.01)$ for forehead wrinkles, and -0.21 units $(\mathrm{p}<0.01)$ for crow's feet, -0.16 units $(\mathrm{p}<0.01)$ for the nasolabial fold, and -0.12 units $(\mathrm{p}<0.05)$ for marionette lines. In order to visualize the effect of the DABBA formulation, we created a facial wrinkle grading map (Fig. 3) based on our facial colour mapping technology (Voegeli et al. 2015). We drew this colour map with the delta values of the active formulation and assigned a pink colour gradient to the map. The darker the pink colour, the greater the delta to baseline was and thus the greater the effect of the formulation. This shows that the main activity of the formulation was in the area of the forehead. In 
(a)

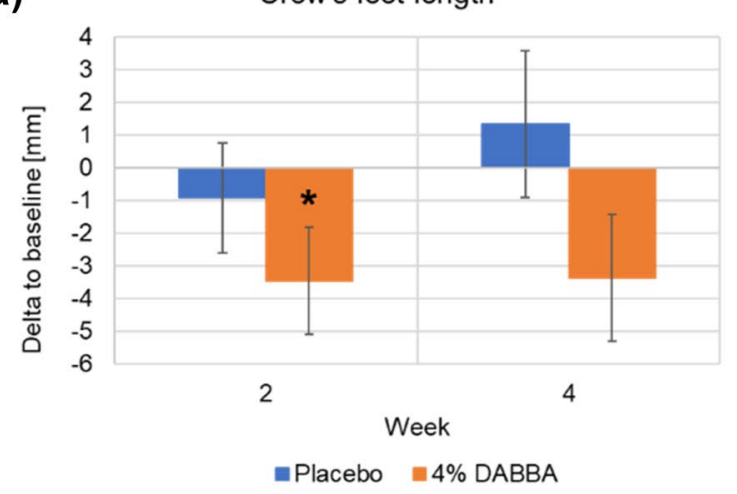

(c)
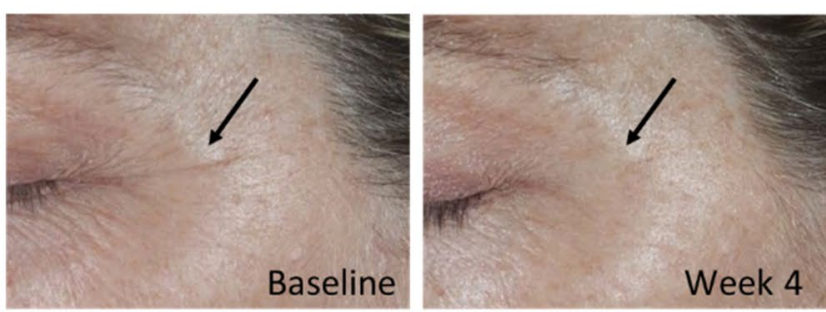

\#8

Fig. 2 Smoothing of crows' feet wrinkles by a formulation containing DABBA as measured by Primos ${ }^{\text {lite }}$. a Crows' feet length was significantly reduced after 2 weeks and stays about the same at 4 weeks. $* \mathrm{p}<0.05$ vs baseline. b Crows' feet area was reduced time-dependently after 2 and 4 weeks. c Volunteer \#8 showing visibly reduced

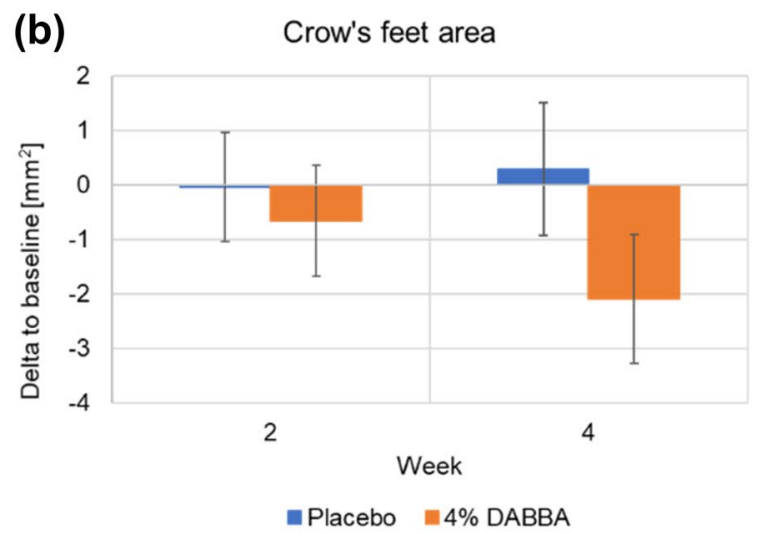

(d)
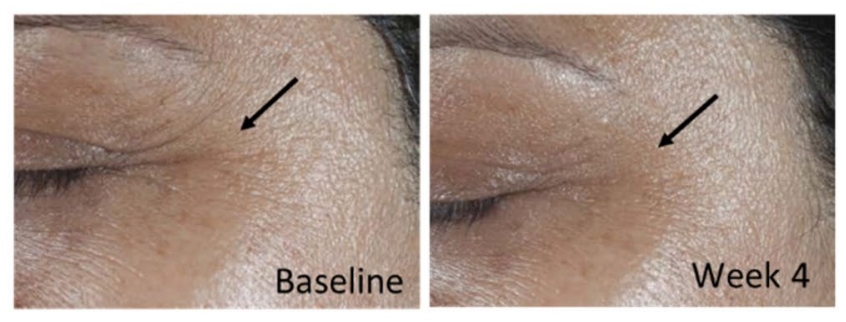

\#52

crows' feet (arrow) at week 4 compared to the baseline. d Volunteer \#52 showing visibly reduced crow's feet (arrow) at week 4 compared to the baseline. Error bars represent standard error of the mean. Student's t-test for paired samples was used
Table 2 Result of expert grading for facial wrinkles

\begin{tabular}{lllll}
\hline Wrinkle area & Formulation & $\begin{array}{l}\text { Delta to baseline at } \\
\text { week 4 [units] }\end{array}$ & SEM & p-value to baseline \\
\hline Forehead & Placebo & -0.11 & 0.05 & 0.11 \\
& 4\% DABBA & -0.26 & 0.06 & $<0.01$ \\
Crow's feet & Placebo & -0.21 & 0.05 & $<0.01$ \\
& 4\% DABBA & -0.21 & 0.05 & $<0.01$ \\
Nasolabial fold & Placebo & -0.11 & 0.04 & $<0.05$ \\
& 4\% DABBA & -0.16 & 0.05 & $<0.01$ \\
Marionette lines & Placebo & -0.09 & 0.05 & 0.13 \\
& $4 \%$ DABBA & -0.12 & 0.04 & $<0.05$ \\
General aging signs (global face) & & & & $<0.05$ \\
Hyperpigmentation & Placebo & -0.14 & 0.05 & $<0.01$ \\
& 4\% DABBA & -0.29 & 0.07 & $<0.05$ \\
Perceived age & Placebo & -0.82 & 0.35 & $<0.05$ \\
\hline
\end{tabular}

Wilcoxon-signed rank test was used SEM standard error of the mean 
Fig. 3 Facial color map of changes in visible wrinkles as assessed by expert grading for the group using the DABBA formulation. Front and side view are shown. The corresponding color map is displayed on the right. The more intense the color, the greater the improvement in wrinkle severity

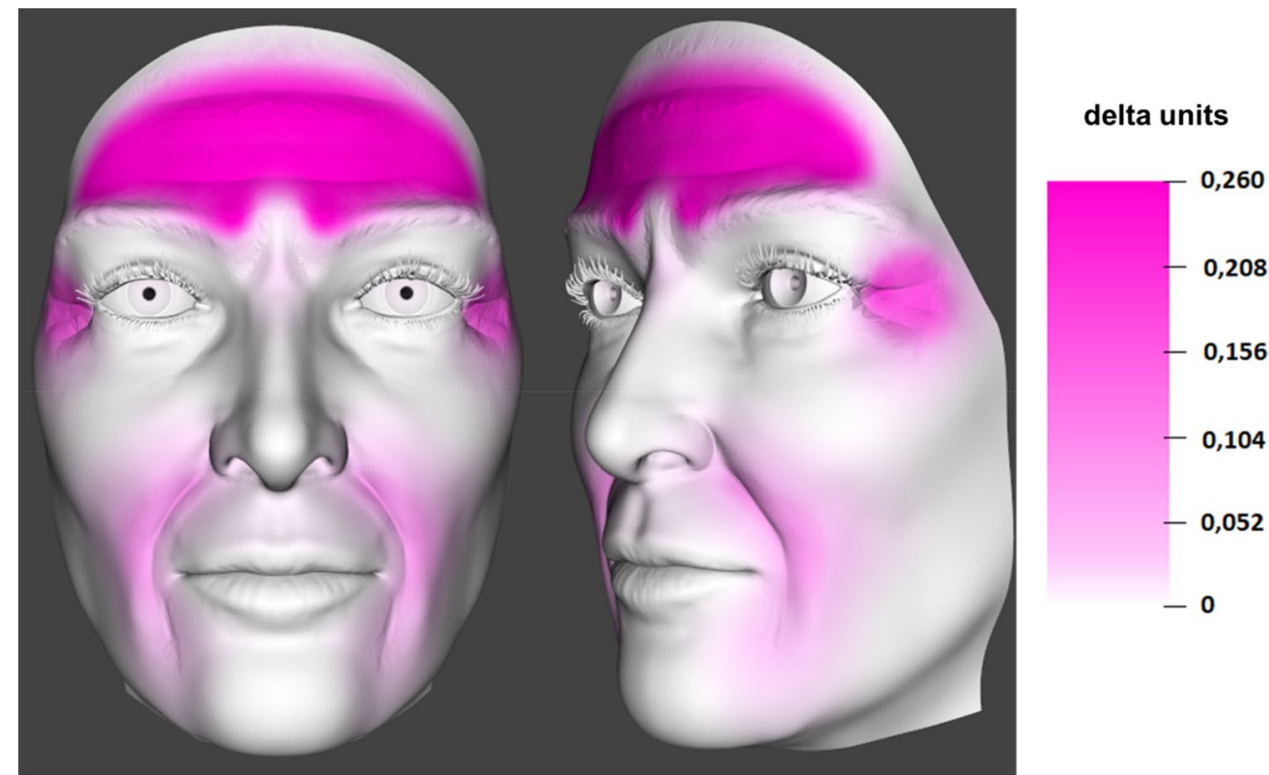

addition to wrinkles, hyperpigmentation and perceived age were reduced, too (Table 2).

\section{The Peptide DABBA is Able to Suppress Mimic Wrinkle Formation on the Forehead}

We analysed the images of the volunteers using a wrinkle segmentation method similar to the one described previously (Campiche et al. 2019). We found a significant reduction in mimic wrinkle formation on the glabella after four weeks in the group using the DABBA formulation compared to the group using the placebo formulation (Fig. 4a, b). Specifically, the wrinkle area was reduced by $13.52 \%(\mathrm{p}<0.05$ vs placebo), wrinkle length was reduced by $14 \%$ ( $\mathrm{p}<0.05$ vs placebo), and wrinkle volume was reduced by $13.59 \%$ ( $\mathrm{p}=0.076$ vs placebo) (Fig. 4c). This reduction in wrinkle formation was visible as shown by volunteer $\# 70$ using the active formulation whereas in volunteer \#43 using the placebo formulation it was not (Fig. 4d). In contrast to the forehead, we did not find a reduction in expressive wrinkle formation on the marionette lines (smiling lines) at the corner of the mouth (Fig. 5). Here, the wrinkle area decreased in the DABBA group compared to the placebo group by $2.9 \%$, wrinkle length decreased by $3.9 \%$, and wrinkle volume decreased by $3.6 \%$ (all non-significant) (Fig. $5 \mathrm{a}-\mathrm{c}$ ). This decrease was slightly visible only in some volunteers, e.g. in \#26 (Fig. 5d).

\section{Discussion}

Expression wrinkles become permanent wrinkles over time (Miyamoto and Hillebrand 2007). They form distinct patterns such as horizontal frown lines on the forehead, vertical lines on the glabella, and crow's feet radiating from the edges of the eyes (Hillebrand et al. 2010). We have conducted a study including biological mother-daughter pairs to investigate the formation, or cutaneous imprinting, of such expressive wrinkle patterns further. The mother-daughter link is not only genetically evident, but also deemed strong across cultures (Bojczyk et al. 2010; Owen-Smith 2003). Thus, daughters share similar ways of behaving and expressing themselves to their mothers. In line with this, we found an intriguing similarity between expression wrinkle patterns on the glabella (Fig. 1b) and the crow's feet (Fig. 1c) of daughters pulling an angry face or smiling and these same wrinkle patterns in their respective mothers when showing a relaxed face. This, together with previously published data (Hillebrand et al. 2010), provides further evidence that expression wrinkles turn into permanent wrinkles over time, and that they can form similar patterns in individuals sharing a similar genetic and emotional background. In view of this, avoiding or suppressing the formation of expression wrinkles has become a widely used method for counteracting permanent wrinkles or smoothening the skin. While in aesthetic dermatology botulinum toxin A is the vehicle of choice for smoothing permanent expression wrinkles (Becker-Wegerich et al. 2001; Small 2014; Song 1998), the cosmetic industry has focused on topical, noninvasive treatments (Campiche et al. 2017; Blanes-Mira et al. 2002). We developed the peptide DABBA which we showed was able to smooth frown lines and crow's feet in vivo (Campiche et al. 2017). Here, we show further evidence for this action on crow's feet wrinkles using Primos $^{\text {lite }}$ (Fig. 2). To emphasize the visible anti-wrinkle activity of the peptide, we performed expert grading on 

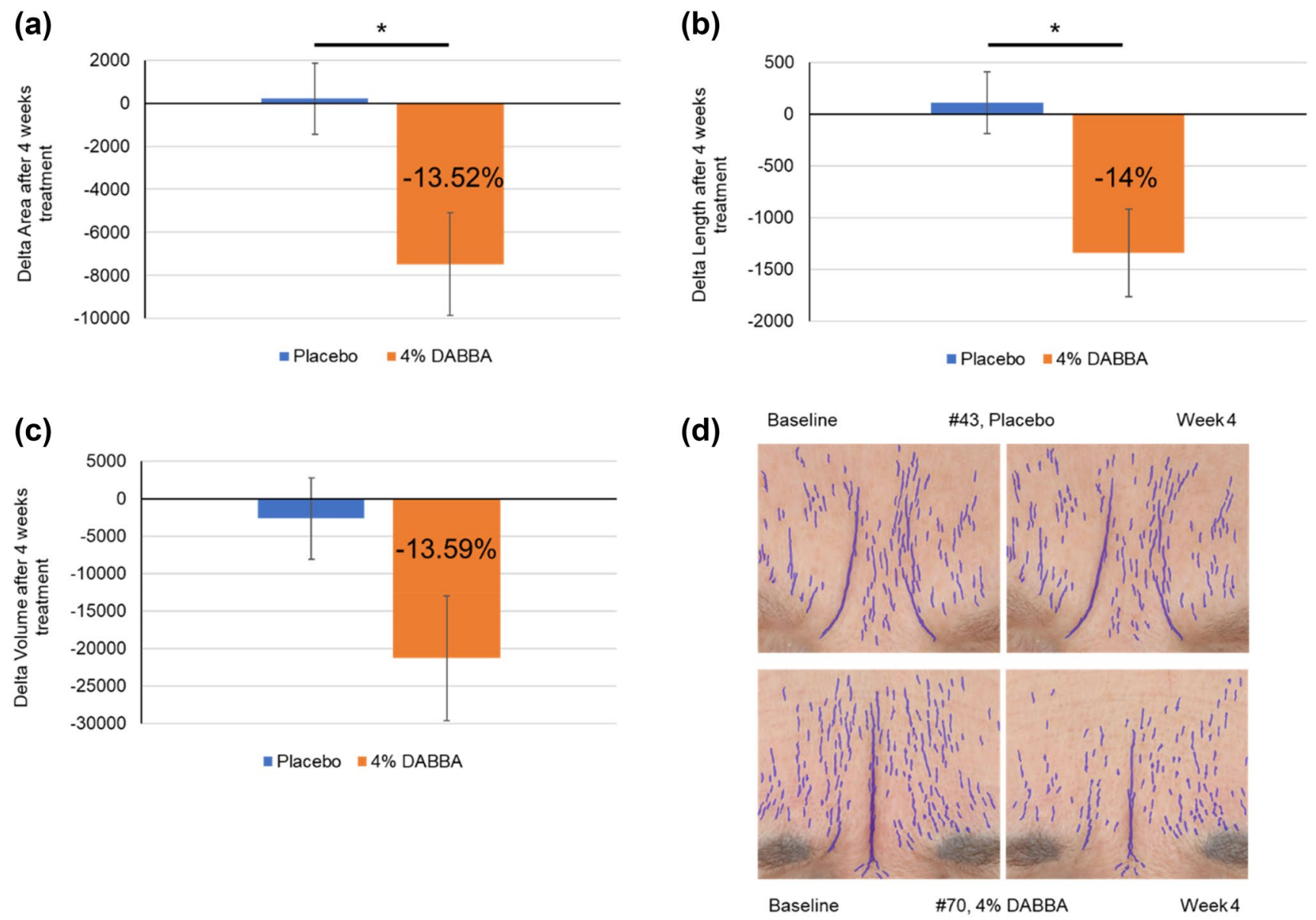

Fig. 4 Effect of DABBA on expression wrinkles on the glabella of an angry face. a Significant decrease of expressive wrinkle area compared to placebo. ${ }^{*} \mathrm{p}<0.05$ vs placebo. $\mathbf{b}$ Significant decrease of expressive wrinkle length compared to placebo. ${ }^{*} \mathrm{p}<0.05$ vs placebo. c Decrease of expressive wrinkle volume compared to placebo. d Images of volunteer \#43 using placebo formulation and volunteer \#70

various areas of the face. There was a visible decrease in wrinkle severity in these facial areas (Table 2). The greatest decrease was seen on the forehead, which is consistent with previous findings for this peptide (Campiche et al. 2017). In addition, perceived age and visible hyperpigmentation decreased, too; indeed, hyperpigmentation decreased by double in the DABBA group compared to the placebo group. Interestingly, we had previously found that the peptide DABBA was able to modulate skin tone in the facial skin of Asian volunteers (Seroul et al. 2020). Often in cosmetic clinical studies we see that the placebo formulation shows a benefit to skin hydration which influences the appearance of skin from fine lines, small wrinkles up to radiance and skin tone, possibly. Here the placebo even yielded significance for some facial areas when assessed by expert grading (Table 2). However, the peptide formulation still showed a better performance for most parameters which together with the other results presented here

using DABBA formulation. There was a visible decrease in wrinkles (blue segmentation) in volunteer \#70 (lower images) which was not seen in volunteer \#43 (upper images). Error bars represent standard error of the mean. Student's t-test for unpaired samples was used for $\mathbf{a}, \mathbf{b}$, and $\mathbf{c}$

suggests the peptide to additionally contribute to the formulation's activity. In order to better visualize the changes in wrinkle severity, we chose to create a wrinkle grading map (Fig. 3) based on our previously published facial color map technology (Voegeli et al. 2015). This technology makes it possible to readily appreciate even small changes in facial parameters such as skin hydration or skin surface pH (Voegeli et al. 2019). In line with this, the changes in facial wrinkles recorded by the expert graders can easily be appreciated on the wrinkle grading map. Since the peptide DABBA is able to reduce expression wrinkles, we investigated whether the ability to express was indeed reduced in volunteers using a formulation containing $4 \%$ of the commercial product after four weeks. Interestingly, we found a significant decrease in wrinkle parameters on the glabella for the active group compared to the placebo group (Fig. 4). However, no clear reduction was found for marionette lines (smile lines) (Fig. 5). We hypothesise 


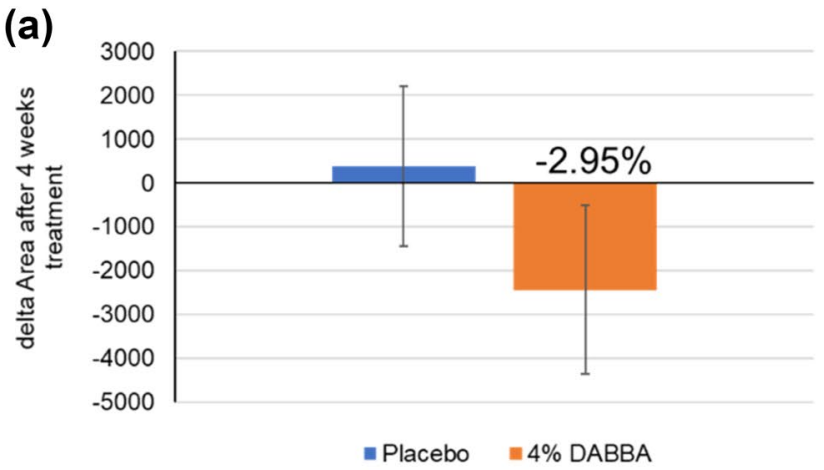

(c)

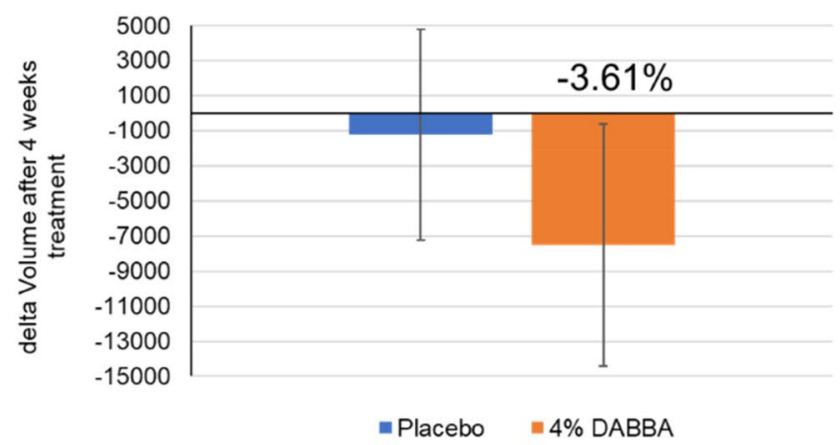

Fig. 5 Effect of DABBA on expression wrinkles on the marionette lines of a smiling face. a through c Only a very small decrease in wrinkles was seen in the active group compared to the placebo group. d Images of volunteer \#17 using placebo formulation and volunteer \#26 using DABBA formulation. There was a small visible decrease in

that this may be due to the thicker skin around the mouth compared to the forehead, and that the thicker skin masked the effect of the peptide in this area. We propose this as substantiation that the peptide is able to modulate facial expression in vivo.

In conclusion, by using a mother-daughter comparison of expressed and relaxed faces, we have shown how expression wrinkles imprint facial skin. We provide further evidence using different methodologies that the peptide diaminobutyroyl benzylamide diacetate helps smoothen facial expression wrinkles, and thus counteracts visible signs of aging. In addition, we present a novel facial colour map based on expert grading for augmented visualization of anti-wrinkle treatments.

Acknowledgements We would like to thank the study volunteers for their participation. We would also like to acknowledge our colleagues for fruitful discussions and comments throughout the project. The (b)

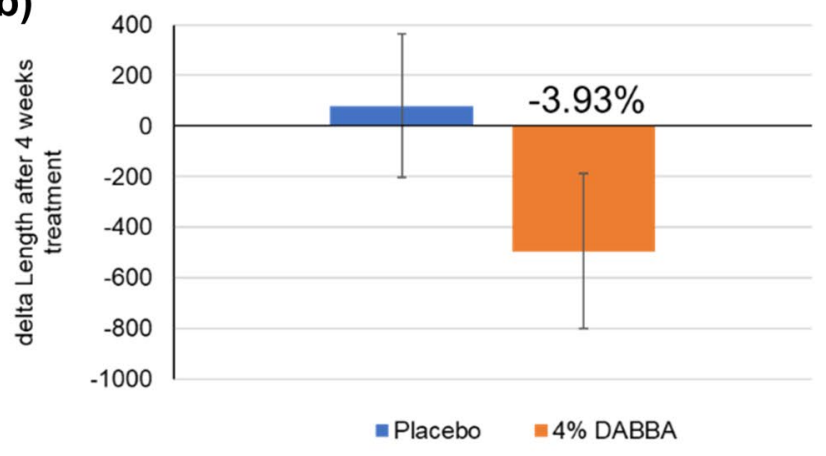

(d)
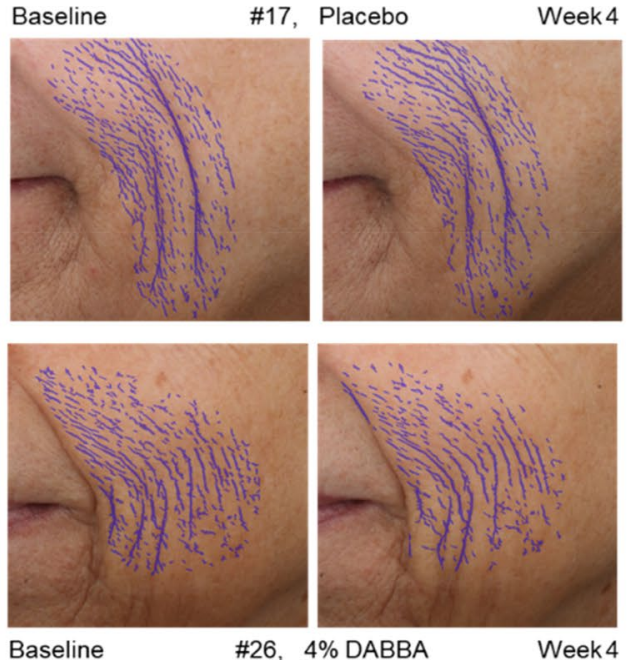

wrinkles (blue segmentation) in volunteer \#26 (lower images) which was not seen in volunteer \#17 (upper images). Error bars represent standard error of the mean. Mann-Whitney $U$ test was used for a and b, Student's t-test for unpaired samples was used for $\mathbf{c}$

peptide diaminobutyroyl benzylamide diacetate (DABBA) is marketed by DSM Nutritional Products under the trade name SYN ${ }^{\circledR}$-AKE.

Open Access This article is licensed under a Creative Commons Attribution 4.0 International License, which permits use, sharing, adaptation, distribution and reproduction in any medium or format, as long as you give appropriate credit to the original author(s) and the source, provide a link to the Creative Commons licence, and indicate if changes were made. The images or other third party material in this article are included in the article's Creative Commons licence, unless indicated otherwise in a credit line to the material. If material is not included in the article's Creative Commons licence and your intended use is not permitted by statutory regulation or exceeds the permitted use, you will need to obtain permission directly from the copyright holder. To view a copy of this licence, visit http://creativecommons.org/licenses/by/4.0/. 


\section{References}

Alam M, Barrett KC, Hodapp RM, Arndt KA (2008) Botulinum toxin and the facial feedback hypothesis: can looking better make you feel happier? J Am Acad Dermatol 58:1061-1072

Bazin R, Doublet E (2007) Skin aging atlas caucasian type. Editions Med'Com, Paris

Bazin R, Leveque JL (2011) Longitudinal study of skin aging: from microrelief to wrinkles. Skin Res Technol 17:135-140

Becker-Wegerich P, Rauch L, Ruzicka T (2001) Botulinum toxin A in the therapy of mimic facial lines. Clin Exp Dermatol 26:619-630

Blanes-Mira C, Clemente J, Jodas G, Gil A, Fernandez-Ballester G, Ponsati B, Gutierrez L, Perez-Paya E, Ferrer-Montiel A (2002) A synthetic hexapeptide (Argireline) with antiwrinkle activity. Int J Cosmet Sci 24:303-310

Blume-Peytavi U, Kottner J, Sterry W, Hodin MW, Griffiths TW, Watson RE, Hay RJ, Griffiths CE (2016) Age-associated skin conditions and diseases: current perspectives and future options. Gerontologist 56(Suppl 2):S230-S242

Bojczyk KE, Lehan TJ, McWey LM, Melson GF, Kaufman DR (2010) Mothers' and their adult daughters' perceptions of their relationship. J Fam Issues 32:452-481

Campiche R, Heidl M, Voegeli R, Imfeld D, Séroul P, Rawlings AV (2017) Synthetic viper venom smooths over a cross-cultural concern. Cosmet Toiletries 132:34-44

Campiche R, Trevisan S, Seroul P, Rawlings AV, Adnet C, Imfeld D, Voegeli R (2019) Appearance of aging signs in differently pigmented facial skin by a novel imaging system. J Cosmet Dermatol 18:614-627

Chavoshnejad P, More S, Razavi MJ (2020) From surface microrelief to big wrinkles in skin: a mechanical in-silico model. Extreme Mech Lett 36:100647

Ekman P, Levenson RW, Friesen WV (1983) Autonomic nervous system activity distinguishes among emotions. Science 221:1208-1210

Franca K, Kumar A, Fioranelli M, Lotti T, Tirant M, Roccia MG (2017) The history of Botulinum toxin: from poison to beauty. Wien Med Wochenschr 167:46-48

Griffiths CE, Wang TS, Hamilton TA, Voorhees JJ, Ellis CN (1992) A photonumeric scale for the assessment of cutaneous photodamage. Arch Dermatol 128:347-351

Hatzis J (2004) The wrinkle and its measurement-a skin surface Profilometric method. Micron 35:201-219

Hillebrand GG, Liang Z, Yan X, Yoshii T (2010) New wrinkles on wrinkling: an 8-year longitudinal study on the progression of expression lines into persistent wrinkles. Br J Dermatol 162:1233-1241

Izard CE (1990) Facial expressions and the regulation of emotions. J Pers Soc Psychol 58:487-498

Jakubietz RG, Kloss DF, Gruenert JG, Jakubietz MG (2008) The ageing hand. A study to evaluate the chronological ageing process of the hand. J Plast Reconstr Aesthet Surg 61:681-686

Kinonen S (2017) This Is the Age You Should Start Preventative Botox. allure https://www.allure.com/story/preventative-botox-age-derma tologists. accessed 08 May 2020.

Krutmann J, Bouloc A, Sore G, Bernard BA, Passeron T (2017) The skin aging exposome. J Dermatol Sci 85:152-161

Kuo IY, Ehrlich BE (2015) Signaling in muscle contraction. Cold Spring Harb Perspect Biol 7:a006023

Kuwazuru O, Saothong J, Yoshikawa N (2008) Mechanical approach to aging and wrinkling of human facial skin based on the multistage buckling theory. Med Eng Phys 30:516-522

Langton AK, Sherratt MJ, Griffiths CE, Watson RE (2010) A new wrinkle on old skin: the role of elastic fibres in skin ageing. Int J Cosmet Sci 32:330-339
Miyamoto K, Hillebrand GG (2007) The influence of facial expression on the age-dependent changes in facial wrinkling. J Cosmet Sci 58:206-207

Nkengne A, Bertin C (2013) Aging and facial changes-documenting clinical signs, part 1: clinical changes of the aging face. SKINmed $11: 281-286$

Nkengne A, Bertin C, Stamatas GN, Giron A, Rossi A, Issachar N, Fertil B (2008) Influence of facial skin attributes on the perceived age of Caucasian women. J Eur Acad Dermatol Venereol 22:982-991

Owen-Smith PL (2003) Mothers and children: feminist analyses and personal narratives, and: the price of motherhood: why motherhood is the most important-and least valued job in America, and: mothers and daughters: connection, empowerment, and transformation (review). NWSA J 15:181-186

Pierard GE, Lapiere CM (1989) The microanatomical basis of facial frown lines. Arch Dermatol 125:1090-1092

Pierard GE, Uhoda I, Pierard-Franchimont C (2003) From skin microrelief to wrinkles An area ripe for investigation. J Cosmet Dermatol 2:21-28

Samson N, Fink B, Matts PJ (2010) Visible skin condition and perception of human facial appearance. Int J Cosmet Sci 32:167-184

Seroul P, Campiche R, Gougeon S, Cherel M, Rawlings AV, Voegeli $R$ (2020) An image-based mapping of significance and relevance of facial skin colour changes of females living in Thailand. Int $\mathbf{J}$ Cosmet Sci 42:99-107

Shin JW, Kwon SH, Choi JY, Na JI, Huh CH, Choi HR, Park KC (2019) Molecular mechanisms of dermal aging and antiaging approaches. Int J Mol Sci 20:2126

Small R (2014) Botulinum toxin injection for facial wrinkles. Am Fam Phys 90:168-175

Song KH (1998) Botulinum toxin type A injection for the treatment of frown lines. Ann Pharmacother 32:1365-1367

Tian L, Xiao S (2016) Facial feature exaggeration according to social psychology of face perception. Comput Graph Forum 35:391-399

Voegeli R, Rawlings AV, Seroul P, Summers B (2015) A novel continuous colour mapping approach for visualization of facial skin hydration and transepidermal water loss for four ethnic groups. Int J Cosmet Sci 37:595-605

Voegeli R, Gierschendorf J, Summers B, Rawlings AV (2019) Facial skin mapping: from single point bio-instrumental evaluation to continuous visualization of skin hydration, barrier function, skin surface $\mathrm{pH}$, and sebum in different ethnic skin types. Int J Cosmet Sci. 41:411-424

Watson RE, Griffiths CE (2005) Pathogenic aspects of cutaneous photoaging. J Cosmet Dermatol 4:230-236

Widgerow AD, Jiang LI, Calame A (2018) A single-center clinical trial to evaluate the efficacy of a tripeptide/hexapeptide antiaging regimen. J Cosmet Dermatol. 18:176

Willis J, Todorov A (2006) First impressions: making up your mind after a 100-ms exposure to a face. Psychol Sci 17:592-598

Zhao Y, Feng B, Lee J, Lu N, Pierce DM (2020) A multi-layered computational model for wrinkling of human skin predicts aging effects. J Mech Behav Biomed Mater 103:103552

Zouboulis CC, Ganceviciene R, Liakou AI, Theodoridis A, Elewa R, Makrantonaki E (2019) Aesthetic aspects of skin aging, prevention, and local treatment. Clin Dermatol 37:365-372

Publisher's Note Springer Nature remains neutral with regard to jurisdictional claims in published maps and institutional affiliations. 